\title{
The Waxing and Waning of Mental Disorders: Evaluating the Stability of Syndromes of Mental Disorders in the Population
}

\author{
Hans-Ulrich Wittchen, Roselind Lieb, Hildegard Pfister, and Peter Schuster
}

\begin{abstract}
This article examines the stability of symptoms, syndromes, and diagnoses of specific anxiety and depressive disorders, as well as diagnostic shifts from one syndrome to another over time. Using retrospective and longitudinal prospective data from the baseline and first follow-up investigation (19.7 months later) of the Early Developmental Stages of Psychopathology Study (EDSP), we focus on establishing stability measures for early stages of mental disorders in a community sample of adolescents aged 14 to 17 years at baseline. The results are as follows: (1) Although only about 30\% developed a full-blown DSM-IV disorder, psychopathological syndromes are widespread in adolescents: $15 \%$ of the population aged 14 to 17 at baseline were not affected by at least some clinically relevant symptoms of mental disorders either throughout their previous life or throughout the follow-up period. (2) The likelihood of staying free of symptoms and threshold disorders during follow-up was highest among subjects who were completely well at baseline. The probability of a positive outcome decreased as a function of severity of baseline diagnostic status. (3) There was a considerable degree of fluctuation not only in the diagnostic status and severity of specific disorders, but also in terms of complete remissions and shifts from one syndrome and disorder to another. (4) Anxiety disorders, overall, slightly differ with regard to the persistence and stability of the diagnostic status from depressive disorders. (5) However, there were remarkable differences between specific types of anxiety and depressive disorders. Consistent with other longitudinal epidemiological studies in the general population, this study finds that the syndromes and diagnoses of mental disorders have a strong tendency to wax and wane over time in this age group.
\end{abstract}

Recent surveys using the standardized diagnostic criteria of the DSM-III- ${ }^{1}$ and DSM-IV ${ }^{2}$ classification systems have demonstrated that between $40 \%$ and $50 \%$ of the adult population have experienced a mental disorder at some point in their lifetime (lifetime prevalence) and $20 \%$ to $25 \%$ fulfilled diagnostic criteria during the previous 12 months. ${ }^{3-8}$ There is a substantial and significant co-occurrence of diagnoses both within and between major classes of disorders, with particularly high lifetime and current comorbidity rates between anxiety and depressive disorders. ${ }^{7-13}$ Additional data on the age of first onset have allowed the incidence of various diagnoses to be identified throughout an individual's life, as well as enabling temporal patterns of diagnosis and co-occurrence of disorders to be identified. ${ }^{4,11,14-19}$ These studies indicate the following:

1. Although the onset of mental disorders can occur at any time in an individual's life, certain mental disorders such as phobic disorders typically begin to emerge in childhood, whereas others such as major depression and generalized anxiety disorder (GAD) usually emerge late in adolescence or (early) adulthood.

2. Consistent with this, studies of comorbid cases also suggest that most comorbid anxiety disorders occur as temporally primary disorders, whereas comorbid depressive disorders are usually secondary. 
3. Data also seem to suggest that the persistence of certain disorders, measured as the continuation from the initial onset in an individual's life to the time of assessment, is quite variable- for example, major depression data, like clinical studies, indicate fairly low persistence coefficients of about $30 \%$ as opposed to anxiety disorders (50\% to $65 \%$ ).

However, methodological issues (categorical assessment of syndromes and temporal resolution of lifetime course of syndromes) and design issues (retrospective studies) make it almost impossible to go beyond such fairly broad estimations about the persistence and stability of mental disorders. Thus, it is not possible at this point to characterize the various forms of mental disorders accurately in terms of duration, variation, and patterns of natural course and outcome (for example, whether there is full or partial remission). In patients with more than 1 disorder (comorbid cases), we also do not know at this point whether and how frequently remission in 1 disorder (for example, agoraphobia) indicates remission for other comorbid conditions (such as depression) or how frequently shifts from one syndrome to another occur. To characterize single disorders in this way (diagnosis-specific characterization) and to produce such characterizations across caseness requires much more subtle assessments of patients' diagnostic status in terms of the presence of symptoms and syndromes over time. Ideally, such an assessment should classify single and multiple diagnostic classes on at least 3 levels: symptomatic, that is, the presence of core symptoms only; subthreshold, meaning that the diagnostic criteria for a full DSM-IV diagnosis are almost met; and threshold, meaning that the full criteria are met. Such data, if available from prospective longitudinal studies, would not only be helpful with regard to our clinical and nosological understanding of specific disorders, but would also assist our understanding of the comorbidity and nosology of mental disorders in general. Such data would (1) help to clarify the importance of suggested symptom progression models, such as those describing the frequent comorbidity patterns of panic, agoraphobia, major depression, and substance use, ${ }^{8,20-}$ ${ }^{23}$ (2) help to determine the nosological status of clinically controversial single diagnoses such as social phobia and GAD, and (3) allow the application of more sophisticated statistical models to identify the latent structure of psychopathology in general.

From the few available longitudinal epidemiological studies in general population samples that offer at least some more subtle information about the diagnostic stability of anxiety and depressive disorders, ${ }^{5,14-16,24}$ the findings seem to suggest that the stability and persistence of specific mental disorders is not as high as previously suggested. ${ }^{2,25}$ In such studies, affective and anxiety disorders were found to have a fluctuating course in terms of the presence and severity over time. Even in what are usually viewed as chronic and persisting conditions such as GAD, there is obviously considerable variability and marked diagnostic instability over time, challenging traditional clinical assumptions. ${ }^{5,26}$

This constitutes a marked difference from the available clinical literature, which frequently describes the natural course of many disorders such as social phobia or GAD, as persisting and sometimes gradually worsening in an almost linear manner, unless treated. The relative lack of stability of symptoms of mental disorders seems especially pronounced in nonclinical studies ${ }^{5,7,27}$ and studies on psychiatric morbidity in primary care settings. ${ }^{28-31}$ This suggests that either the course of epidemiological cases differs from that of clinical samples or, alternatively, retrospective clinical findings concerning the course of mental disorder provide biased estimates of the true natural course of anxiety and depressive disorders. 


\section{Objecitves}

This article examines the stability of symptoms, syndromes, diagnoses, and caseness of various specific mental disorders, defined by DSM-IV criteria, in more detail. Using retrospective and longitudinal prospective data from the baseline and the first follow-up investigation of the Early Developmental Stages of Psychopathology Study (EDSP) ${ }^{32,33}$ and considering various diagnosis-specific and caseness-threshold models (well, symptomatic, subthreshold, and threshold), we focus on establishing stability measures for early stages of mental disorders. We emphasize that we are concerned with the patterns of the natural course of mental disorders that are characteristic of early stages of the disorders. The findings might not be representative of mental disorders as a whole. The following questions are addressed:

1. What were the lifetime and 12-month prevalence rates at the time of the baseline study and at follow-up of DSM-IV anxiety and depressive disorders among adolescents?

2. How frequent was comorbidity in this sample of adolescents? Which conditions occurred most frequently as primary disorders and which most frequently as secondary disorders?

3. How stable were symptoms, syndromes, and diagnoses of mental disorders over time?

\section{Method}

This article reports findings from the baseline and first follow-up investigation of the EDSP. The EDSP examined the prevalence, risk factors, comorbidity, and course of mental disorders and substance use disorders prospectively over a period of almost 5 years in a representative sample of 3,021 subjects aged 14 to 24 years at the time of the baseline study. The study provides the opportunity for up to 2 prospective follow-up interviews (the time difference between investigations being approximately 19 months) during adolescence and early adulthood, when the incidence of anxiety, affective disorders, and substance disorders and the development of comorbidity is high. Emphasis is placed on the evaluation of developmental patterns of psychopathology in early adolescence through early adulthood, after the age of 14 . Childhood disorders prior to this age (such as conduct disorder, attention-deficit/hyperactivity disorder, and oppositional defiant disorder) that might be important precursor conditions for subsequent psychopathology were mainly assessed in a separate part of the project by interviewing the parents of our respondents; these findings will be reported in a separate publication.

Important features of the EDSP study include (1) an interview based on a modified version of the Composite International Diagnostic Interview (CIDI) ${ }^{34}$ adapted to evaluate DSM-IV ${ }^{2}$ and ICD $-10^{35}$ research diagnostic criteria, (2) the assessment of a broader range of threshold and subthreshold diagnoses and syndromes than previous surveys, and (3) the use of memory-aid techniques introduced by the National Comorbidity Survey ${ }^{7}$ to improve the recall for onset and disabilities associated with past episodes of disorders. The EDSP sample of 14- to 24year-old subjects has also been chosen to minimize the effect of recall bias while maximizing its usefulness in estimating baseline prevalence and estimating incidence in our subsequent waves.

\section{Design}

The overall design of the study (Fig 1) is prospective and longitudinal with a family history component. It consists of a baseline survey (conducted in 1995) and 2 follow-up surveys at 
approximately 15 and 30 months after the baseline (first follow-up study conducted, on average, 19.7 months after the baseline study). In a separate parent investigation, direct personal interviews were performed with the respondents' parents to assess information about the respondents' somatic, psychological, and childhood social development and childhood disorders, and to assess symptoms, syndromes, and diagnoses of mental disorders in the family. Findings presented herein include data from the baseline and first follow-up investigation of adolescents aged 14 to 17 at the time of the baseline study.

\section{Sample}

The total sample was drawn from the 1994 Bavarian government registry of inhabitants in metropolitan Munich (and the surrounding district--for details, see Wittchen et al.32). Table 1 summarizes the number and percentage at the baseline study conducted in 1995 and at the first follow-up conducted in 1997-1998, on average, 19.7 months later, with the completion rates for males and females (for a more detailed description of this sample, see Höfler et al. ${ }^{36}$ and Perkonigg et al. ${ }^{37}$ ).

To account for differential sampling probabilities in this study, as well as nonresponses, data reported herein have been adjusted by age, sex, and geographic location to match the distribution of the sampling frame (for further details, see Wittchen et al. ${ }^{32}$ and Nelson and Wittchen ${ }^{38}$ ).

\section{Diagnostic Assessment}

Symptom and diagnostic assessments in the baseline study and the first follow-up investigation were based on the Computer- Assisted Personal Interview (CAPI) lifetime (TO) and follow-up change (T1) version of the Munich-Composite International Diagnostic Interview (M-CIDI). ${ }^{39,40}$ The M-CIDI is a modified version of the World Health Organization CIDI, version 1.2, supplemented with questions to cover DSM-IV and ICD-10 criteria. The M-CIDI allows for the assessment of symptoms, syndromes, and diagnoses of 48 mental disorders (not counting various subtypes of main disorders) along with information about onset, duration, and clinical and psychosocial severity. This report particularly emphasizes affective disorders (including mania, bipolar I and II, major depression, and dysthymia) and anxiety disorders (including panic disorder, agoraphobia, GAD, specific, social, and separation anxiety disorders, and phobia NOS). The remaining diagnoses (such as eating and substance use disorders, obsessive-compulsive disorders, and posttraumatic stress disorders) are collapsed into "other disorders" and are not dealt with separately herein.

Diagnostic analysis is based on the M-CIDI diagnostic package DSM-IV diagnostic algorithms. ${ }^{40}$ Diagnostic findings reported herein are based on the M-CIDI/DSM-IV algorithms without using the DSM-IV hierarchy rules unless otherwise stated. We deleted most of the CIDI skip rules in the CIDI diagnostic sections to allow the study of various forms of subthreshold conditions (see below), which also include clinically defined subthreshold forms such as mixed anxiety-depression and brief recurrent anxiety/depression. In this way, we also improved the CIDI ability to measure more subtle changes in diagnostic status. For the purpose of this report, we classify the diagnostic status of all respondents for each diagnosis, as well as across all diagnoses (caseness status), into 4 mutually exclusive groups using the polytomous DSM-IV criteria:

- Well: no core symptoms for the respective diagnosis 
- Symptomatic: at least 1 diagnostically relevant core symptom and some additional symptoms (for example, at least 1 subjective panic attack that came unexpectedly);

- Subthreshold: DSM-IV criteria almost fully met except for 1 key criterion (for example, all criteria for panic disorder are met, but only 2 instead of 4 of the mandatory autonomic symptoms)

- Threshold: full DSM-IV criteria are met

The mean time taken to complete the computerized CAPI M-CIDI, including the questionnaires, was 77 minutes. The decision to use the CAPI-CIDI was made after pilot testing in which CAPI interviews were shown to reduce the length of interview administration, and this helped to avoid interviewer coding errors, skip-rule errors, and probequestion errors. The CAPI version of the M-CIDI was supplemented by a separate respondent booklet that included several scales and questionnaires of importance to the longitudinal component of our study. There were also cognitive aids to assist the respondent in dating symptom onset and occurrence and in answering complicated symptom questions and identifying patterns in the course of his or her disorder.

\section{Reliability and Validity of the M-CIDI}

The psychometric properties of the M-CIDI have been investigated in various types of samples (see Reed et al. ${ }^{41}$ and Wittchen et al. ${ }^{33}$ ). The test-retest reliability of the computerized M-CIDI has been investigated in a sample of 60 community respondents. They were interviewed twice independently by trained interviewers with an average time interval of 38 days between investigations. Test-retest reliability was good for almost all specific DSM-IV core symptom questions and disorders examined, with $\mathrm{K}$ values ranging from fair (bulimia, $\mathrm{K}$ $=0.55$; GAD, $\mathrm{K}=0.45)$ to excellent $(\mathrm{K}>0.72)$ for all other anxiety disorders and alcohol use disorders. ${ }^{33}$ Validity was investigated in a clinical sample of 68 patients by comparing MCIDI diagnoses with clinical diagnoses made by treating physicians. There was generally good concordance between clinician and M-CIDI diagnoses, with the exception of psychotic disorders $(K=0.21)$, dysthymia $(0.54)$, and somatoform disorders $(0.50)$. The $K$ values for the remaining categories ranged from 0.63 for panic disorder to 0.96 for depressive episode (see Reed et al. ${ }^{41}$ ).

\section{Fieldwork}

Face-to-face computer-assisted interviews were administered by professional health interviewers and clinical psychologists at the baseline study, and exclusively by trained clinical psychologists at follow-up. All interviewers received intensive CIDI training, which included the CIDI standard training components. The training period was followed by practice interviews, which were closely monitored by our staff. In the fieldwork, after initiating contact with the proband by mail, the time and location of the direct interview were agreed upon by telephone. Most interviews were conducted in the homes of the probands. During the fieldwork, all interviewers were closely supervised by specially trained M-CIDI clinical editors. Thus, errors in the later interviews could be minimized and missing values could be reassessed immediately.

\section{Results}

Baseline and Follow-up Prevalence and Incidence of M-CIDI/DSM-IV Disorders 
Table 2 reports the number and weighted prevalence (with 95\% confidence interval [CI]) at baseline and follow-up. The last column indicates the cumulative lifetime incidence for each condition over the course of the study. At follow-up, the incidence (proportion of cases with the disorder unaffected at baseline) and 12-month prevalence at follow-up are reported separately (proportion of cases with an active disorder at follow-up irrespective of diagnostic status at baseline). For baseline and follow-up, we also provide a crude stability measure. This measures indicates the proportion of current 12-month cases among all lifetime cases, observed at either baseline or follow-up.

At baseline, 33.3\% of all 14- to 17-year-olds had at least 1 disorder listed, most of whom also fulfilled criteria for at least 1 disorder during the 12 months preceding the interview (12month prevalence, $24.0 \%$; 12 -month to lifetime prevalence ratio, $72 \%$ ). The 12 -month prevalence of disorders at follow-up was considerably higher (31.4\%), mainly due to recent incident cases (25.2\%) that were not suffering from any mental disorder at baseline. The follow-up stability (12-month follow-up prevalence to cumulative incidence 63\%) is slightly lower than at baseline. The overall cumulative incidence of diagnoses among adolescents aged 14 to 17 at baseline is $50.1 \%$, indicating that every second individual fulfilled diagnostic criteria for at least 1 disorder once in his or her lifetime. Rates of comorbidity were quite high overall, and increased slightly over the observation period (baseline, 13.0\% comorbid v $20.3 \%$ pure; follow-up, $22.7 \%$ comorbid v $27.4 \%$ pure).

Prevalence patterns of specific diagnoses differed considerably between baseline and followup. The 12-month prevalence of any depressive disorder (baseline, 4.8\%; 8.6\% at follow-up), substance use disorder (7.2\%; 12.9\%), and somatoform disorder (2.4\%; 5.8\%), for example, increased considerably during the follow-up period, whereas the 12-month prevalence for any anxiety disorder declined from $14.5 \%$ to $10.4 \%$. This indicates, in accordance with previous age-of-onset hazard analyses, ${ }^{42}$ that anxiety disorders are mostly early-onset disorders, with few incident cases after early adolescence, whereas substance and somatoform and affective disorders usually occur later in adolescence or have a more fluctuating course.

\section{Baseline and Follow-up Changes in Caseness Status of Mental Disorders}

Table 3 provides a cross-tabulation of the respondents' caseness status at baseline and followup using 4 different CIDI caseness definitions: well, symptomatic, subthreshold, and threshold. Whereas "threshold" indicates that the person fulfilled full DSM-IV diagnostic criteria at least once, "well" describes subjects who did not even show symptoms of any mental disorder examined. "Symptomatic" denotes subjects endorsing at least some symptoms for at least 1 disorder, and "subthreshold" indicates the group in between symptomatic and threshold.

Of the total of 1,228 subjects examined, 315 described themselves as free of any core symptoms of mental disorders at baseline, and 53.2\% of these remained well (without any signs of psychopathology) through the follow-up period; $19 \%$ changed to symptomatic and $17.3 \%$ to subthreshold, and only $10.5 \%$ developed a threshold disorder. In contrast, of 365 threshold subjects at baseline (with any DSM-IV diagnosis), only 16.7\% were completely well at follow-up, $21.4 \%$ were symptomatic, $26.2 \%$ were subthreshold, and $35.7 \%$ fulfilled diagnostic criteria for at least 1 disorder. Overall, the estimated probability of threshold caseness for any DSM-IV diagnosis at follow-up increased as a function of baseline diagnostic status. It is also noteworthy that for both subthreshold and threshold cases, the estimated probability of the individual concerned being at least a subthreshold case again at 
follow-up is remarkably high (51.9\% for baseline subthreshold cases and 61.9\% for baseline threshold cases).

\section{Baseline Versus Follow-up: Depressive and Anxiety Disorders}

When reading Tables 4 and 5, it should be noted that each diagnostic status in the left part of the cross-tabulation (well, symptomatic, subthreshold, or threshold) only refers to the particular condition to which it was applied for each individual. Thus, a person whose depression has completely remitted at follow-up (and is therefore "well" in terms of depression) might still have another disorder present (see the following section). The righthand portion of the cross-tabulation reports the estimated probability for other threshold DSM-IV diagnoses to inform about the frequency of other disorders at follow-up in each of the baseline groups.

Depressive disorder. For depression (either major depression and/or dysthymia), a similar overall picture emerged as for overall caseness. The estimated probability of being classified as a threshold or subthreshold depression case at follow-up increased fairly consistently as a function of diagnostic status at baseline. For example, $81.8 \%$ of the total of 936 subjects unaffected by depressive symptoms at baseline remained well; only a few developed symptoms of depression (8.3\%), subthreshold depression (4.8\%), or threshold depression (5.1\%). In contrast, the respective follow-up conditional probabilities among 104 baseline threshold depression cases were 39.2\% well, 9.7\% symptomatic, $20.1 \%$ subthreshold, and $31.0 \%$ threshold. The estimated probability of having an anxiety disorder at follow-up was also considerably higher (21.6\%). No such relationship, however, was found for other diagnoses examined.

Taking threshold and subthreshold depression status together, the data suggest that $31.5 \%$ to $51.1 \%$ of all baseline subthreshold and threshold cases were again classified as at least subthreshold cases. When considering dysthymia and major depression cases separately, dysthymia cases appeared to have a slightly less favorable outcome than major depression cases.

Anxiety disorder. Anxiety disorder, overall, showed a slightly different picture from depressive disorders in 3 respects:

- A considerably lower proportion of stable threshold cases $(19.7 \% \mathrm{v} 31.0 \%)$

- A considerably lower proportion of new threshold cases as compared with depression

- An increased risk of depressive disorder

However, as with depression, the estimated probability of threshold caseness at follow-up increased as a function of baseline status. Another noteworthy finding is that, unlike depression, cases with no anxiety or only symptomatic anxiety at baseline had a fairly low risk of also having other disorders.

An inspection of the findings for specific diagnoses (not shown in the Tables) revealed considerable variability. Taking stable threshold and subthreshold diagnoses both at baseline and at follow-up as a yardstick, panic disorder (44\%) and specific phobia (30.1\%) were found to be most stable, whereas specific phobia NOS (4\%), agoraphobia (13.4\%), and social phobia (15.8\%) were the least stable. Complete remissions for specific threshold diagnoses were correspondingly highest for specific phobia NOS (93\% of cases were complete remissions) and agoraphobia (75.4\%). 


\section{How "Well" Are "Remitted" Baseline Anxiety and Depression Cases ?}

The remarkable number of baseline threshold cases with depression and anxiety that were found to be completely free of symptoms at follow-up raises the question of whether these cases are completely remitted or whether they had other threshold diagnoses present. Figure 2A indicates that $70.7 \%$ of baseline depression cases that remitted at follow-up have no other diagnoses of any type; $10.4 \%$, however, had anxiety disorders and $16.4 \%$ other disorders (predominantly somatoform disorders) and $2.6 \%$ were found to have multiple diagnoses.

However there are several noteworthy differences when major depression and dysthymia are considered separately. Just 2 individuals had dysthymia only, whereas 11 fulfilled criteria for both major depression and dysthymia. Among the 39 remitted baseline major depression cases, only 63.4\% were actually completely free of mental disorders, 9.1\% fulfilled criteria for dysthymia at follow-up, $8.6 \%$ had an anxiety disorder, and $17 \%$ had other disorders (either somatoform or substance use disorders). A slightly less favorable follow-up diagnostic status was found for dysthymia - only $47.3 \%$ with remitted dysthymia were free of other disorders (differences were all nonsignificant).

Figure 2B shows that, overall, anxiety disorders (87.3\%; 95\% CI 80.4\%-94\%) had a significantly higher proportion of completely remitted cases than depressive disorders (70.7\%; 95\% CI 62.1\%- 79.2\%). Only a few had depressive or other disorders. There is, however, remarkable variation between the different types of anxiety disorders, suggesting that this result is mainly driven by specific phobia and phobia NOS cases.

Of the 26 remitted agoraphobia cases (threshold agoraphobia at baseline and no symptoms at followup), $12.9 \%$ fulfilled criteria for other anxiety disorders, $8.3 \%$ for depressive disorders, $3.6 \%$ for other diagnoses (exclusive somatoform), and $10.6 \%$ for all of these conditions (resulting in a complete remission rate of $64.6 \%$; 95\% CI 52.0\%- 72.1\%), but $78.8 \%$ of specific phobia cases and 82\% (95\% CI 72.5\%-91\%) of phobia NOS cases were completely remitted at follow-up. The lowest complete remission rates (with no further diagnoses) were found for panic disorder (50\%) and GAD (22\%).

\section{Discussion}

The main aim of this report was to investigate, retrospectively and prospectively, the stability of symptoms, syndromes, and diagnoses of anxiety and depressive conditions over a mean period of 19.7 months in a representative population sample of adolescents and young adults aged 14 to 17 years at baseline.

Before discussing our findings, some limitations and caveats should be mentioned. (1) A key characteristic of our study is that we relied exclusively on diagnostic information provided by the adolescents and did not include either available clinical information about the diagnostic status and course of the disorders or parents' reports, which might be of relevance, especially for some early-onset anxiety and somatoform disorders. We were encouraged to take this approach by our findings that the M-CIDI diagnoses considered herein are at least sufficiently reliable and valid. ${ }^{32,41}$ (2) Our findings apply exclusively to adolescents and not necessarily to older respondents and disorders, where the stability and persistence of syndromes, as well as comorbidity, might be more pronounced. (3) Throughout the report, we emphasize a descriptive approach. Thus, differences between diagnostic groups should be interpreted with caution due to the considerable CIs. (4) No attempt was made to monitor the course, 
persistence, and remission of disorders in a more detailed way as a function of time by using survival modeling or additional information that might have enabled us to monitor the course of disorders on a monthly basis. (5) Finally, no attempt was made to control for the influence of comorbid conditions at baseline or to investigate the role of gender, because of the fairly low base rates. Keeping these potential limitations in mind, there are at least 5 noteworthy findings and observations:

1. Psychopathological syndromes were widespread. We found that symptoms of mental disorder occurred in the vast majority of adolescents studied, a finding that is consistent with results from a comparable epidemiological study in this field. ${ }^{3}$ Only slightly more than $15 \%$ of the population aged 14 to 17 at baseline were not affected by at least some clinically relevant symptoms of mental disorder either throughout their lives prior to investigation or throughout the follow-up period. We can further conclude that the likelihood of staying free from any mental symptoms (53.2\%) - and even more importantly, free from mental disorders $(89.5 \%)$ - throughout the follow-up period is highest among subjects who were well at baseline and that this probability of a positive outcome decreases as a function of severity of baseline diagnostic status. In the baseline study, only $86.3 \%$ of individuals with symptoms of disorders remained free from other diagnoses during follow-up; among subthreshold cases, $74.4 \%$, and among baseline threshold cases, only $64.3 \%$, did not develop any other mental disorder. In terms of caseness, this seems to suggest a dimensional structure of psychopathology ${ }^{43}$; however, one should note that the "symptomatic" diagnostic status category used in this study seems much closer to the "well" category than to the "subthreshold" and "threshold" categories.

2. In the age group of adolescents studied, there was a considerable degree of fluctuation not only in the diagnostic status and severity of specific disorders but also in terms of complete remissions and shifts from one syndrome and disorder to another. Shifts between anxiety and affective disorders, but also to somatoform and substance use disorders, are particularly frequent. This finding is in accordance with earlier observations in prospective epidemiological studies by Angst et al. ${ }^{27}$ and Vollrath and Angst. ${ }^{14}$

3. Depressive symptoms and disorders affect a considerable proportion of even young adolescents and were found to be surprisingly persistent, at least whenever the point of subthreshold diagnostic status was reached. More than $50 \%$ of all baseline threshold cases and one third of the baseline subthreshold cases were still cases at least on the subthreshold level at follow-up. Even though we did not examine whether the depressive symptoms were present during the full follow-up period or whether there were recurring episodes, this clearly signals that adolescent depression is not typically a rare, transient phenomenon. This finding is not significantly influenced by the slightly less favorable outcome for dysthymic disorders.

4. A slightly different overall picture emerged for anxiety disorders. First, contrary to our expectations and traditional clinical wisdom, anxiety disorders were not more persistent than depressive disorders. We observed a slightly higher proportion of full remissions to the "well" status for anxiety disorders than for depressive disorders and a lower proportion of persistent threshold and subthreshold cases. The demonstration that this finding is mainly driven by the most prevalent specific phobia and phobia NOS suggests that, at least in this age group, there was obviously a significant proportion of transient developmental but nevertheless clinically significant phobias with a favorable natural course, likely to remit completely without any comorbid condition present. Although the specific diagnostic stability of threshold conditions of panic disorder and GAD was also low overall, the follow-up outcome was considerably less favorable. As expected, we found that what are usually considered as more severe forms 
of DSM-IV anxiety disorder only rarely remit completely if shifts to other diagnoses or lower diagnostic thresholds are considered. Social phobias were found to have a relatively unstable course of progression, with $62 \%$ of baseline threshold cases being completely remitted. Only $16 \%$ remained threshold cases over the follow-up period. However, even among remitted baseline threshold social phobia cases, there was an increased risk of depressive and other threshold disorders, similar to GAD and panic disorder. Thus, in the future, more detailed prospective longitudinal analyses of the role of adolescent social phobia, in particular, deserve further attention.

5. The analyses of diagnostic shifts to other disorders (comorbidity) suggest, for both anxiety and depressive disorders, that diagnostic remission for one condition does not necessarily mean complete remission for at least one third of the sample. Rather, we found, e.g., for social phobia, that although $62.8 \%$ of baseline threshold social phobia cases were well at follow-up, many had other affective, somatoform, or anxiety disorders present at follow-up. Thus, there is obviously considerable "mobility" between diagnostic classes in terms of syndromes and diagnoses.

Finally, it should also be emphasized that retrospective assessment of the stability of syndromes and diagnoses obviously results in much higher rates of persistence and stability. It is not entirely clear whether the markedly lower prospective stability measures, as compared with the retrospective measures, are merely an artifact of different assessment methodologies or whether they reflect a true finding. We favor the assumption that such retrospective persistence measures frequently used in epidemiological surveys 7 are most likely to lead to a serious overestimation of stability.

To conclude, this study is in line with previous data from adult prospective longitudinal studies in the general population, which have shown that symptoms and syndromes, as well as diagnoses, of mental disorders wax and wane over time. ${ }^{3}$ 


\begin{tabular}{|c|c|c|c|}
\hline & Total & Men & Women \\
\hline 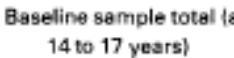 & \multicolumn{3}{|c|}{ Baseline sample total lage } \\
\hline $\mathrm{N}$ (\% of the sample) & 1877 & $963(51,3)$ & $914(49.7)$ \\
\hline \multicolumn{4}{|l|}{ Completed interviews } \\
\hline \multicolumn{4}{|l|}{ Baseline 1995 (TO) } \\
\hline $\mathrm{N}$ & 1,395 & 714 & 681 \\
\hline Response rate $(\%)$ & 74.3 & 74.1 & 74.5 \\
\hline \multicolumn{4}{|l|}{ Completed interviews } \\
\hline \multicolumn{4}{|c|}{ Follow-up 1996/1997 [T1]* } \\
\hline $\mathrm{N}$ & 1228 & 637 & 591 \\
\hline Response rate $(\%)$ & 88.0 & 692 & 86.8 \\
\hline
\end{tabular}

-First follow-up investigation was conducted on average

19.7 months after baseline (range, 15 to 25.6 months).

Table 2. Prevalenee and Ineidence of M-CIDLDSM-IV Mental Disorders at Baseline and Follow-up in a Sample of Respondents From the EDSP Study, Aged 14 to 17 Years at Buseline

\begin{tabular}{|c|c|c|c|c|c|c|c|c|c|c|c|c|c|c|c|c|c|}
\hline & \multicolumn{7}{|c|}{ Besedine } & \multicolumn{10}{|c|}{ Folow-up } \\
\hline & \multicolumn{3}{|c|}{ Lihetime } & \multicolumn{3}{|c|}{12 Morth } & \multirow[b]{2}{*}{ Stabiliny } & \multicolumn{3}{|c|}{ 12-Menth } & \multicolumn{3}{|c|}{ Incidenon } & \multirow[b]{2}{*}{ Stability } & \multicolumn{3}{|c|}{ Dumulation TOT/* } \\
\hline & $\mathrm{Naw}$ & Sow & $95 \% \mathrm{Cl}$ & $\operatorname{Now}$ & Sw & s6\%o & & $\mathrm{New}$ & $\mathrm{Now}$ & $95 \% \mathrm{Ca}$ & $\mathrm{Nw}$ & Sw & $95 \times \mathrm{Cl}$ & & $\mathrm{Nw}$ & sw & $95 \% \mathrm{Cl}$ \\
\hline Any diegnosist & 409 & 33.3 & $30.4-36.2$ & 296 & 24.0 & $21.4-26.7$ & 0.72 & 385 & 31.4 & $28.5-34.2$ & 206 & 25.2 & $220-28.4$ & 0.63 & 615 & 50.1 & $47.1-53.1$ \\
\hline 1 & 249 & 20.3 & 17.8 .22 .8 & & & & & 278 & 22.7 & $20.1-25.2$ & & & & & 337 & 27.4 & $24.7-30.2$ \\
\hline $2+$ & 160 & 13.0 & $10.9-15.1$ & & & & & 107 & 8.7 & $6.9-10.5$ & & & & & 278 & 22.7 & $20.1-25.3$ \\
\hline \multicolumn{18}{|l|}{ Any substance } \\
\hline ordert & 104 & 8.5 & 6.6-10.3 & 88 & 7.2 & $5.5-8.9$ & 0.85 & 158 & 12.9 & $10.8-14.9$ & 123 & 10.9 & $9.0-12.9$ & 0.70 & 227 & 18.5 & $16.0-20.9$ \\
\hline \multicolumn{18}{|l|}{ Any affective } \\
\hline disorder & 130 & 10.6 & $8.7-12.6$ & 86 & 7.0 & 548.5 & 0.66 & 136 & 11.0 & $9.1-13.0$ & 92 & 8.4 & $6.6-10.1$ & 0.61 & 222 & 18.1 & $15.7-20.5$ \\
\hline Bipolar I & 15 & 1.2 & $0.6-1.9$ & 15 & 1.2 & $0.5-1.8$ & 0.95 & 16 & 1.3 & $0.6-2.0$ & 14 & 1.2 & $0.5 \cdot 1.8$ & 0.54 & 29 & 2.4 & $1.5-3.3$ \\
\hline Bipolar II & 19 & 1,5 & $0.7-2.4$ & 15 & 1.2 & $0.5-2.0$ & 0.90 & 14 & 1,1 & $0.8-1.7$ & 12 & 10 & $0.4-1.5$ & 0.46 & 31 & 2.5 & $1.5-3.5$ \\
\hline \multicolumn{18}{|l|}{ Any depressive } \\
\hline disorder & 99 & 8.0 & $6.3-9.8$ & 59 & 4.8 & $3.5-6.1$ & 0.59 & 106 & 8.6 & $6.9-10.3$ & 76 & 6.7 & $5.1-8.3$ & 0.60 & 175 & 14.2 & $12.1-16.4$ \\
\hline MDD & 82 & 6.7 & 5.18 .3 & 42 & 3.4 & 23.4 .6 & 0.52 & 83 & 6.8 & $5.2-8.3$ & 68 & 6.0 & $4.5-7.5$ & 0.56 & 150 & 12.2 & $10.2-14.3$ \\
\hline Dysthymia & 21 & 1.7 & $1.0-2.4$ & 19 & 1.6 & $0.9-2.3$ & 0.93 & 27 & 2.2 & $1.3-3.1$ & 22 & 1.8 & $1.0-2.7$ & 0.63 & 43 & 3.5 & $2,4-4.6$ \\
\hline \multicolumn{18}{|l|}{ Any anxiety dis. } \\
\hline order & 282 & 21.3 & $18.9-23.8$ & 178 & 14.5 & $12.4-16.6$ & 0.68 & 128 & 10.4 & 8.6-12.3 & 78 & 8.0 & 6. $1-10.0$ & 0.38 & 340 & 27.7 & $25.0-30.4$ \\
\hline Panic attacks & so & 3.2 & 2.1 .4 .3 & 24 & 1,9 & $1.1-2.8$ & 0.60 & 43 & 3.5 & 2.3 .4 .7 & 32 & 2.7 & $1.6-3.7$ & 0.61 & 71 & 5.8 & $4.4-7.2$ \\
\hline \multicolumn{18}{|l|}{$\begin{array}{l}\text { Panic diagnosis } \\
\text { with or } \\
\text { without agora- }\end{array}$} \\
\hline phobia & 9 & 0.7 & $0.2-1.2$ & 4 & 0.3 & 0.0 .0 .7 & 0.45 & 10 & 0.8 & $0.3-1.4$ & 7 & 0.6 & $0.1-1.0$ & 0.65 & 16 & 1.3 & $0.6-2.0$ \\
\hline \multicolumn{18}{|l|}{$\begin{array}{l}\text { Agoraphobia } \\
\text { without panic }\end{array}$} \\
\hline disorder & 29 & 2.4 & $1.4 \cdot 3.3$ & 24 & 1.9 & 1.0 .2 .8 & 0.82 & 10 & 0.8 & $0.3-1.3$ & 8 & 0.7 & $0.1-1.2$ & 0.27 & 37 & 3.0 & $1.9-4.1$ \\
\hline Phobia NOS & 74 & 6.0 & $4.6-7.4$ & 35 & 2.9 & $1.9-3.9$ & 0.48 & 27 & 2.2 & 1.43 .1 & 24 & 21 & $1.2-3.0$ & 0.28 & 98 & 8.0 & $6.4-9.6$ \\
\hline Social phobia & 46 & 3.7 & $2.6-4.8$ & 36 & 2.9 & $1.8-3.9$ & $0 . \pi 7$ & 28 & 2.3 & $1.4-3.3$ & 25 & 2.1 & $1.2-3.0$ & $0 . \infty 0$ & 71 & 5.8 & 4.3 .72 \\
\hline Specific phobis & 169 & 13.7 & $11.7-15.8$ & 110 & 9.0 & $7.3 \cdot 10.7$ & 0.65 & 71 & 5.8 & 4.3 .72 & 41 & 3.9 & 2.6 .5 .2 & 0.34 & 210 & 17.1 & $14.8-19.4$ \\
\hline \multicolumn{18}{|l|}{$\begin{array}{l}\text { Generalizad } \\
\text { anxiety dis- }\end{array}$} \\
\hline order & 4 & 0.3 & $0.0-0.7$ & 3 & 0.2 & $0.0-0.6$ & 0.80 & 1 & 0.1 & $0.0-0.2$ & 1 & 0.1 & $0.0-0.2$ & 0.19 & 5 & 0.4 & $0.0-0.8$ \\
\hline \multicolumn{18}{|l|}{$\begin{array}{l}\text { Obeessive com- } \\
\text { pulsive dis. }\end{array}$} \\
\hline onder & 7 & 0.6 & $0.1-1.1$ & 3 & 0.3 & $0.0-0.6$ & 0.47 & 3 & 0.2 & $0.0-0.4$ & 3 & 0.2 & $0.0-0.4$ & 0.26 & 10 & 0.8 & $0.2-1.3$ \\
\hline \multicolumn{18}{|l|}{ Posttraumatic } \\
\hline stress disorder & 6 & 0.5 & $0.0-1.0$ & 3 & 0.3 & 0.0 .0 .6 & 0.57 & 4 & 0.3 & 0.0 .0 .7 & 2 & 0.2 & $0.0-0.4$ & 0.49 & 8 & 0.7 & $0.1-1.2$ \\
\hline \multicolumn{18}{|l|}{ Ary sating disor- } \\
\hline $\operatorname{det}$ & 14 & 1.1 & $0.4-1.8$ & 13 & 1.0 & $0.4-1.7$ & 0.90 & 12 & 1.0 & $0.3-1.6$ & 12 & 1.0 & $0.3-1.6$ & 0.46 & 26 & 2.1 & 1.1 .30 \\
\hline \multicolumn{18}{|l|}{ Amy somatoform } \\
\hline disonder! & 38 & 3.1 & 1.9 .4 .2 & 29 & 2.4 & $1.3-3,4$ & 0.76 & 71 & 5.8 & 4.3 .72 & 63 & 5.3 & $3.9-6.7$ & 0.70 & 101 & 8.2 & $6.5-99$ \\
\hline
\end{tabular}

"Cumulated lifetime incidence TarT1.

tOf the diagnoses below.

tNicotine dependence is excluded

5Not used for summary.

TAnorexia nervosa, untypical anorexia nervosa, bulimia nervosa, atypical bulimia nervosa.

|SSI 4/6, hypochondriasis, pain disorder. 
Table 3. Crosstabulation of Casesness Status at Baseline and Follow-up in a Community Sample of 1,228 Adolescents

\begin{tabular}{|c|c|c|c|c|}
\hline \multirow[b]{2}{*}{ Diagnecatic Status at Baseline } & \multicolumn{4}{|c|}{ Conditions: Probstility 1\%, 95\% C11 for Dagnastic Status at follow-up } \\
\hline & WellNoSpmptoms & Sympoomatic & Subthreshold & Threshold \\
\hline \multirow[t]{2}{*}{ Wellino symptoms $[n=315$ ) } & 53.2 & 19.0 & 17.3 & 10.5 \\
\hline & $(47.3-59.1)$ & {$[14.5-23.5]$} & $(12.8-21.8$ 아 & {$[6.8 \cdot 14.2]$} \\
\hline \multirow[t]{2}{*}{ Symptomatic $(n=190)$} & 35.0 & 26.6 & 24.7 & 13.7 \\
\hline & $(27.8-42.2)$ & $\{20.0-33.5\}$ & $(18.0-31.4\}$ & $(8.7-18.7)$ \\
\hline \multirow[t]{2}{*}{ Subthreshold (n = 358) } & 27.3 & 20.8 & 26.3 & 25.6 \\
\hline & $\{22.3-32.3\}$ & $\{16.2-25.5\}$ & $(21,4-31.1)$ & $|20.6-30.6\rangle$ \\
\hline \multirow[t]{2}{*}{ Threshold ( $n-365$ ) } & 16.7 & 21.4 & 26.2 & 35.7 \\
\hline & $\{12.4 \cdot 20.9\}$ & $\{16.7-26.1\}$ & $(21.2-31.2)$ & $|30.3-41.2\rangle$ \\
\hline
\end{tabular}

Table 4. Crosstabulation: Conditional Probability of Depression Caseness at Follow-up Given the Respective Baseline Depression Status

\begin{tabular}{|c|c|c|c|c|c|c|}
\hline \multirow[b]{3}{*}{ Status at Baseline } & \multicolumn{6}{|c|}{ Conditional Probability (\%), 95\% Cl) of Olagnostic Status at Follow-up } \\
\hline & \multicolumn{4}{|c|}{ Depression } & \multicolumn{2}{|c|}{ Other Disgnoses } \\
\hline & WellNo Symphoms & Symptomatic & Subshreshold & Threshold & Anxilety Disorder" & Other Diagneses $t$ \\
\hline Wellino symptoms (n - 936) & $\begin{array}{c}\mathbf{8 1 . 8} \\
(79.1 .84 .5)\end{array}$ & $\begin{array}{c}8.3 \\
(6.4-10.3)\end{array}$ & $\begin{array}{c}4.8 \\
(3.3-6.3)\end{array}$ & $\begin{array}{c}5.1 \\
\langle 3.6-6.7\rangle\end{array}$ & $\begin{array}{c}8.2 \\
\langle 6.3-10.1\}\end{array}$ & $\begin{array}{c}16.1 \\
(8.1-24.0)\end{array}$ \\
\hline Symptomatic in $=98$ ) & $\begin{array}{c}72.7 \\
{[63.1-82.4)}\end{array}$ & $\begin{array}{c}7.5 \\
(1.7-13.4)\end{array}$ & $\begin{array}{c}6.8 \\
(1.5-12.1)\end{array}$ & $\begin{array}{c}12.9 \\
(5.5-20.3)\end{array}$ & $\begin{array}{c}9.1 \\
\langle 3.0-15.1)\end{array}$ & $\begin{array}{c}13.0 \\
(5.6-20.5)\end{array}$ \\
\hline Subthreshold ( $n=91$ ) & $\begin{array}{c}56.0 \\
(44.7 .67 .4)\end{array}$ & $\begin{array}{c}12.4 \\
(4.7 \cdot 20.2)\end{array}$ & $\begin{array}{c}11.3 \\
(3.8-18.8)\end{array}$ & $\begin{array}{c}20.2 \\
(11.1-29.3)\end{array}$ & $\begin{array}{c}22.2 \\
\mid 2.3-32.1\}\end{array}$ & $\begin{array}{c}14.7 \\
(7.1 .22 .3)\end{array}$ \\
\hline Threshold $(n-104)$ & $\begin{array}{c}39.2 \\
(28.7-49.8)\end{array}$ & $\begin{array}{c}9.7 \\
(3.3-16.1)\end{array}$ & $\begin{array}{c}20.1 \\
(11.1-29.1)\end{array}$ & $\begin{array}{c}31.0 \\
(21.0-41.0)\end{array}$ & $\begin{array}{c}21.6 \\
(13.0-30.1)\end{array}$ & $\begin{array}{c}7.8 \\
(5.9-9.7)\end{array}$ \\
\hline
\end{tabular}

-Anxiety disorders covered: panic disorder, agoraphobis, specific, social phobis, GAD.

tOther diagnoses covered: somatoform, eating disorders, PTSO, OCD, bipolar I and II.

Table 5. Crosstabulation: Conditional Probability of Any Anxiety Disorder Caseness at Follow-up Given the Respective Baseline Anxiety Status

\begin{tabular}{|c|c|c|c|c|c|c|}
\hline \multirow[b]{3}{*}{ Sestus at Eabetine } & \multicolumn{6}{|c|}{ Conditionel Probability $\mid \mathrm{K}, 95 \% \mathrm{CD}$ of Disgnostic Status at Foliow up } \\
\hline & \multicolumn{4}{|c|}{ Any Anxiety } & \multicolumn{2}{|c|}{ Other Diagnoess } \\
\hline & WelliNo Symptoms & Symptomatic & Subthreshold & Thresthold & Deproseive disorder" & Other diagnosest \\
\hline \multirow{2}{*}{ Wellino symptoms ( $n=438$ ) } & 74.5 & 13,9 & 6.0 & 5.7 & 5.2 & 5.5 \\
\hline & $(70.5-78.6)$ & (10.8-16.9) & $\langle 3.7-8.2\rangle$ & $(3.6-7.7)$ & $\langle 3.1 \cdot 7.3\rangle$ & $(3.3-7.7)$ \\
\hline \multirow[t]{2}{*}{ Symptomatic $\langle n=240\rangle$} & 58.1 & 26.8 & 7.8 & 7.3 & 5.7 & 7.3 \\
\hline & {$[51.5-64.6)$} & $(21,1-32,4)$ & $(4.3-11.3)$ & $\{3.7-10.9\}$ & $(2.5-8.9\rangle$ & $(4,1-10,4)$ \\
\hline \multirow{2}{*}{ Subthreahold in = 187) } & 48.4 & 24.7 & 11.7 & 15.3 & 15.2 & 17.5 \\
\hline & $\{40.4-56.3\}$ & $(17.6-31.8)$ & $(6.8-16.5)$ & $(9.2-21.4)$ & $\{10.3-21.1\}$ & $|11.3 \cdot 23.6\rangle$ \\
\hline \multirow[t]{2}{*}{ Threshold ( $n=263$ ) } & 38.2 & 26.3 & 15.8 & 19.7 & 13.5 & 12.0 \\
\hline & $(31.9-44.5\rangle$ & $\{20.5-32,1\}$ & $(11.1-20.6)$ & $(14.5-24.8)$ & $(10.1-17.9)$ & $(7.7-16.2)$ \\
\hline
\end{tabular}

*Anxiety disorders covered: panic disorder, agoraphobia, specific, social phobia, GAD.

tOther diagnoses convered: somatoform, eating disorders, PTSD, OCD, depressive disorders, bipolar 1 and II.

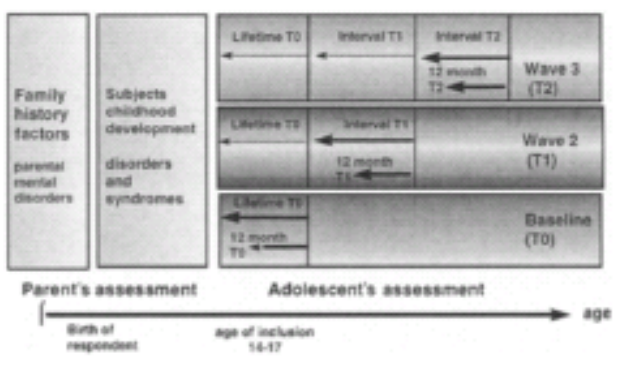

Fig 1. EDSP design and diagnostic intormation. 



\section{References}

1. American Psychiatric Association. Diagnostic and Statistical Manual of Mental Disorders (ed. 3, rev.). Washington, DC: APA, 1987.

2. American Psychiatric Association: Diagnostic and Statistical Manual of Mental Disorders (ed. 4). Washington, DC: APA, 1994.

3. Angst J, Dobler-Mikola A. The Zurich Study. VI. A continuum from depression to anxiety disorders.'? Eur Arch Psychiatry Neurol Sci 1985 ;235:179-186.

4. Robins LN, Regier DA (eds). Psychiatric Disorders in America. The Epidemiologic Catchment Area Study. New York, NY: Maxwell Macmillan International, 1991.

5. Wittchen H-U, von Zerssen D. Verläufe behandelter und unbehandelter Depressionen und Angststörungen.- Eine klinisch-psychiatrische und epidemiologische Verlaufsuntersuchung. Berlin, Germany: Springer, 1987.

6. Wittchen H-U, Essau CA, Zerssen D, Krieg J-C, Zaudig M. Lifetime and six-month prevalence of mental disorders in the Munich Follow-up Study. Eur Arch Psychiatry Clin Neurosci 1992;241:247258.

7. Kessler C, McGonagle KA, Zhao S, Nelson CB, Hughes M, Eshleman S, et al. Lifetime and 12month prevalence of DSM-III-R psychiatric disorders in the United States: Results from the National Comorbidity Survey. Arch Gen Psychiatry 1994;51:8-19.

8. Wittchen H-U, Nelson CB, Lachner G. Prevalence of mental disorders and psychosocial impairments in adolescents and young adults. Psychol Med 1998;28:109-126.

9. Boyd JH, Burke JD, Grnenberg E, Holzer CE, Rae DS, George LK, et al. Exclusion criteria of DSM-III: A study of co-occurrence of hierarchy-free syndromes. Arch Gen Psychiatry 1984;41:983989.

10. Regier DA, Farmer ME, Rae S, Locke BZ, Keith S J, Judd LL, et al. Comorbidity of mental disorders with alcohol and other drug abuse. Results from the Epidemiologic Catchment Area (ECA) study. JAMA 1990;264:2511-2518.

11. Wittchen H-U. What is comorbidity. Fact or artefact? (Editorial). Br J Psychiatry 1996; 168(Suppl 30):7-8.

12. Merikangas K, Angst J, Eaton W, Canino G, Rubio-Stipec M, Wacker H, et al. Comorbidity and boundaries of affective disorders with anxiety disorders and substance abuse: results of an international task force. Br J Psychiatry 1996; 168(Suppl 30):49-58. 
13. Kessler RC, Stang CP, Wittchen H-U, Ustun TB, Roy-Burne PP, Walters EE. Lifetime panicdepression comorobidity in the National Comorbidity Survey. Arch Gen Psychiatry 1998;55:801-808. 14. Vollrath M, Angst J. Outcome of panic and depression in a seven-year follow-up: results of the Zurich study. Acta Psychiatr Scand 1989;80:591-596.

15. Angst J. Comorbidity of mood disorders: a longitudinal prospective study. Br J Psychiatry 1996; 168(Suppl 30):22-28.

16. Angst J, Merikangas K, Scheidegger P, Wicki W. Recurrent brief depression: a new subtype of depressive disorder. J Affect Disord 1990;19:87-98.

17. Burke KC, Burke JD, Regier DA, Rae D. Age of onset of selected mental disorders in five community populations. Arch Gen Psychiatry 1990;47:511-518.

18. Magee WJ, Eaton WW, Wittchen H-U, McGonagle KA, Kessler RC. Agoraphobia, simple phobia, and social phobia in the National Comorbidity Survey. Arch Gen Psychiatry 1996;53:159-168.

19. Oldehinkel A, Wittchen H-U, Schuster P. Prevalence, 20-month incidence and outcome of unipolar depressive disorders in adolescents. Psychol Med. In Press.

20. Lewinsohn PM, Hops H, Roberts RE, Seeley JR, Andrews JA. Adolescent psychopathology: I. prevalence and incidence of depression and other DSM-III-R disorders in high school students. J Abnorm Psychol 1993;102:133-144.

21. Kessler RC, Nelson CB, McGonagle KA, Liu J, Swartz M, Blazer DG. Comorbidity of DSM-III-R major depressive disorder in the general population: results from the US National Comorbidity Survey. Br J Psychiatry 1996; 168(Suppl 30):8-21.

22. Kessler RC, Crum RM, Warner LA, Nelson CB, Schulenberg J, Anthony JC. Lifetime cooccurrence of DSM-III-R alcohol abuse and dependence with other psychiatric disorders in the National Comorbidity Survey. Arch Gen Psychiatry 1997;54:313-321.

23. Swendsen JD, Merikangas KR, Canino GJ, Kessler RC, Rubio-Stipec M, Angst J. The comorbidity of alcoholism with anxiety and depressive disorders in four geographic communities. Compr Psychiatry 1998;39:176-184.

24. Feehan M, McGee R, Williams SM. Mental health disorders from age 15 to age 18 years. J Am Acad Child Adolesc Psychiatry 1993;32:1118-1126.

25. Michels R, Cooper AM, Guze SB, Judd LL, Solnit AJ, Stunkard AJ, et al (eds). Psychiatry. Mental Disorders. Philadelphia, PA: Lippincott, 1993.

26. Kessler R, Edlund MJ, Frank RG, Kendler KS, Leaf PJ, Nelson CB, Wittchen H-U. Comorbidity of DSM-III-R disorders and substance disorders in the National Comorbidity Survey. Menninger. In Press.

27. Angst J, Merikangas K. The depressive spectrum: diagnostic classification and course. J Affect Disord 1997;45:31-39.

28. Ormel J, Koeter MW, van den Brink W van de Willige G. Recognition, management, and course of anxiety and depression in general practice. Arch Gen Psychiatry 1991 ;48:700-706.

29. Ormel J, Oldehinkel T, Brilman E. Outcome of depression and anxiety in primary care. A threewave 3 1/2-year study of psychopathology and disability. Arch Gen Psychiatry 1993; 50(10):759-766.

30. Tiemens BG, Ormel J, Simon GE. Occurrence, recognition and outcome of psychological disorders in primary care. Am J Psychiatry 1996;153:636-644.

31. Pini S, Tansella M, Wittchen H-U, Perkonigg A. Prevalence, recognition and 12-month outcome of mental disorders in primary care. Am J Psychiatry. In Press.

32. Wittchen H-U, Perkonigg A, Lachner G, Nelson CB. Early developmental stages of psychopathology study (EDSP): objectives and design. Eur Addict Res 1998;4:18-27.

33. Wittchen H-U, Lachner G, Wunderlich U, Pfister H. Test-retest reliability of the computerized DSM-IV version of the Munich-Composite International Diagnostic Interview (MCIDI). Soc Psychiatry Psychiatry Epidemiol 1998;33:568-578.

34. World Health Organisation. Composite International Diagnostic Interview (CIDI): a) CIDIinterview (version 1.0), b) CIDI-user manual, c) CIDI-training manual d) CIDI-computer programs. Geneva, Switzerland: World Health Organisation, 1990.

35. World Health Organization: ICD-10, chapter V. Mental and Behavioral Disorders (including disorders of psychological development). Diagnostic criteria for research. Draft for field trials. Geneva, Switzerland: World Health Organization, 1991. 
36. Höfler M, Lieb R, Perkonigg A, Schuster P, Sonntag H, Wittchen H-U. Covariates of cannabis use progression in a representative population sample of adolescents: a prospective examination of vulnerability and risk factors. Addiction 1999;94: 1679-1694.

37. Perkonigg A, Lieb R, Höfler M, Schuster P, Sonntag H, Wittchen H-U. Patterns of cannabis use, abuse and dependence in adolescents: prevalence, incidence and symptom progression. Addiction 1999;94:1663-1678.

38. Nelson CB, Wittchen H-U: Editorial. The EDSP: setting the stage! Eur Addict Res 1998;4:5-7. 39. Wittchen H-U, Beloch E, Garczynski E, Lachner G, Perkonigg A, Pfister H, et al. Münchener Composite International Diagnostic Interview (M-CIDI, paper-pencil 2.2, 2/95).

Max-Planck-Institut für Psychiatry, München, Germany: Eigendruck, 1995.

40. Wittchen H-U, Pfister H (eds). DIA-X-Interviews: Manual für Screening-Verfahren und Interview; Interviewheft Längsschnittuntersuchung (DIA-X-Lifetime); Ergänzungsheft (DIA-X-Lifetime);

Interviewheft Querschnittuntersuchung (DA-X-12 Monate); Ergänzungsheft (DIA-X-12 Monate); PCProgramm zur Durchführung des Interviews (Längs- und Querschnittuntersuchung);

Auswertungsprogramm. Frankfurt, Germany: Swets \& Zeitlinger, 1997.

41. Reed V, Gander F, Pfister H, Steiger A, Sonntag H, Trenkwalder C, et al. To what degree the Composite International Diagnostic Interview (CIDI) correctly identifies DSM-IV disorders? Testing validity issues in a clinical sample. Int J Meth Psychiatr Res 1998;7:142-155.

42. Wittchen H-U, Lieb R, Schuster P, Oldehinkel AJ. When is onset? Investigations in early developmental stages of anxiety and depressive disorders. American Psychiatric Press. In Press. 43. Goldberg DP, Gater R, Sartorius N, et al. The validity of two versions of the GHQ in the WHO study of mental illness in general health care. Psychol Med 1997;27:191-197. 